\title{
ACTIVISMO VERDE.
}

\section{PARTICIPACIÓN CIUDADANA POR EL DERECHO AL AMBIENTE SANO EN LA ARGENTINA}

\author{
JULieta MiRA \\ Investigadora UBACyT en el Instituto de Investigaciones Gino Germani, Facultad de \\ Ciencias Sociales, Universidad de Buenos Aires \\ julieta_mira@yahoo.com.ar
}

Recibido: 4 de octubre de 2016 / Aceptado: 16 de enero de 2017

RESUMEN: Este trabajo aborda la participación ciudadana en materia ambiental en la Argentina desde una doble perspectiva: la expresión de la protesta socioambiental y la implementación de los mecanismos formales previstos en la legislación. La perspectiva adoptada es interdisciplinaria, pues integra una mirada social con el derecho. Para ello, se analizan, por una parte, la configuración del movimiento social, que se focaliza en la toma de la calle y en la visibilización de la problemática ambiental, y, por otra, la legislación, los casos judiciales y las sentencias de la Corte Suprema de Justicia de la Nación.

Con este propósito, se presentan tres casos emblemáticos de conflicto ambiental sucedidos a inicios del siglo XXI: "No a la mina" en Esquel (provincia del Chubut); "No a las papeleras. Sí a la vida" en Gualeguaychú (provincia de Entre Ríos); y el reclamo para el saneamiento ambiental de la cuenca Matanza-Riachuelo (provincia de Buenos Aires y Ciudad Autónoma de Buenos Aires). Como aporte central, en este texto se despliega la relevancia del activismo verde mediante la elaboración de una tipología de la participación ciudadana y un repertorio de buenas prácticas en torno al reclamo del derecho constitucional a un ambiente sano para las generaciones presentes y futuras. 
RESUM: Aquest treball aborda la participació ciutadana en matèria ambiental a l'Argentina en una doble definició: d'una banda, l'expressió de la protesta socioambiental; de l'altra, la implementació dels mecanismes formals previstos en la legislació. La perspectiva adoptada és així interdisciplinària, atès que integra les mirades social i del dret. Amb aquesta finalitat s'analitza, d'una banda, la configuració dels moviments socials que posen el focus en prendre els carrers i visibilitzar la problemàtica ambiental, i d'altra banda, la legislació, casos judicials i sentències del Tribunal Suprem de Justícia de la Nació (d'Argentina).

Així, es presenten tres casos emblemàtics de conflicte ambiental d'inicis del segle XXI: "No a la mina" a Esquel (Província de Chubut); "No a les papereres" a Gualeguaychú (Província d'Entre Ríos); i la demanda de sanejament ambiental a la conca del riu Matanza-Riachuelo (Província de Buenos Aires i Ciutat Autònoma de Buenos Aires).

A mode de contribució central, el text desplega la rellevància de l'activisme verd, mitjançant l'elaboració d'una tipologia de la participació ciutadana i d'un repertori de bones pràctiques relatives a la reivindicació del dret constitucional a un ambient sa per a les generacions presents i futures.

ABSTRACT: This paper approaches the community participation into environmental matters in Argentina in a double sense: as an expression of the social-environmental protest, and as the implementation of formal legal mechanisms. The perspective adopted is interdisciplinary integrating social and legal frameworks. For this reason is analysed, on the one hand, the configuration of the social movements focused on street demonstrations; and, on the other hand, the law, judicial cases and decisions settled by the Supreme Court of Justice.

With this aim are presented three emblematic cases of environmental conflict which took place in the beginning of the 21st century: "Not to the mine" in Esquel (Province of Chubut); "Not to the paper mill”" in Gualeguaychú (Province of Entre Ríos); and the claim for the environmental reparation of the Matanza-Riachuelo River Basin (Province of Buenos Aires and Autonomous City of Buenos Aires).

Finally, this paper sets out the relevancy of the green activism, across elaborating a typology of civil participation and a digest of good practices around the claim of the constitutional right to a healthy environment for present and future generations. 
PALABRAS CLAVE: Conflicto socioambiental - Participación ciudadana - Minería a cielo abierto - Plantas de celulosa - Cuenca Matanza-Riachuelo.

PARAULES CLAU: Conflicte socioambiental - Participació ciutadana - Mineria a cel obert -Plantes de cel·lulosa - Conca del riu Matanza-Riachuelo.

KEYWORDS: Social-environmental Conflict-Community Participation-Surface Mining —Paper Mills — Matanza-Riachuelo River Basin.

Sumario: I. Introducción: la acción colectiva por el derecho al ambiente sano. II. Desarrollo: la participación ciudadana en conflictos ambientales. 1. Marco teórico-conceptual. 2. Mecanismos formales en la legislación. 3. Casos emblemáticos: Esquel, Gualeguaychú y cuenca Matanza-Riachuelo. 4. Tipología de las acciones colectivas y estrategias de incidencia. III. Conclusiones: la fuerza del activismo verde. IV. Anexos. 1. Constitución de la república argentina. 2. Ley general del ambiente. 3. Ley de la cuenca Matanza-Riachuelo. 4. Ley de libre acceso a la información ambiental. V. Bibliografía. 1. Bibliografía citada y consultada. 2. Jurisprudencia. 3 . Sitios en internet.

\section{INTRODUCCIÓN: LA ACCIÓN COLECTIVA POR EL DERECHO AL} AMBIENTE SANO

En este trabajo me propongo indagar las formas de participación ciudadana vinculadas a los conflictos ambientales y su impacto en la gestión de la vida pública en la Argentina ${ }^{1}$, ya que el derecho al ambiente sano configura un derecho de incidencia colectiva — de uso común e indivisible - por excelencia de acuerdo con el artículo 41 de la Constitución Nacional de la República Argentina. La participación, en cuanto derecho a tomar parteen la creación de las leyes, fue caracterizada como "el derecho de los derechos" por William

\footnotetext{
${ }^{1}$ Quiero reconocer con gratitud que la idea de este artículo fue inspirada en las clases de la materia "Derecho de Incidencia Colectiva" dictada por el Prof. Osvaldo Sidoli, en la carrera de abogacía en la Facultad de Derecho de la Universidad de Buenos Aires (UBA). Le agradezco muy especialmente al Dr. Carlos Cárcova haberme abierto las puertas del Instituto de Investigaciones Jurídicas y Sociales Ambrosio Gioja de la Facultad de Derecho de la UBA, donde realicé este trabajo como investigadora invitada. Le agradezco también a Emilio Tamburini su generosa ayuda con la traducción del resumen de este artículo a la lengua catalana. Asimismo, es un gusto expresar un sincero reconocimiento a los evaluadores anónimos ya que gracias a sus precisos comentarios estimularon la mejora del presente artículo, como así también a los correctores de la RCDA por su impecable y esmerada labor.
} 
COBBETT $^{2}$. En esta misma línea de pensamiento, también es posible establecer para la participación ciudadana un paralelo con el derecho a la protesta social, al ser ambas expresiones sociales fuente promotora de la protección de derechos en una democracia representativa y aún más cuando se aspire a avanzar hacia una democracia participativa o hacia un ideal de autogobierno. Roberto GARGARELLA señala que este derecho constituye el "primer derecho" porque es el derecho a protestar por los demás derechos, de ahí la relevancia de "preservar ámbitos adecuados para la expresión de la crítica social"3.

Existe "un principio hostil a la intervención ciudadana en el control de los asuntos públicos", sostiene GARGARELLA, a la vez que también señala lo siguiente: "Es difícil no estar de acuerdo con la idea de que la ausencia de un intenso activismo cívico se vincula, al menos en parte, con la previa ausencia de instituciones capaces de alentar dicho activismo, y con la presencia de otras que lo desalientan"4. Comparto esta visión de GARGARELLA que me acompaña como guía para la reflexión sobre la participación de "ciudadanos públicamente comprometidos"5 que se desarrolla en estas páginas.

En la Argentina "el nivel de protesta socio-ambiental no ha cesado con el paso del tiempo; sólo considerando los reclamos vinculados con la explotación de los recursos naturales, existen en la actualidad más de 40 puntos de conflicto en, al menos, 12 provincias", concluye Andrés NAPOLI en el Informe Ambiental Anual 2014de la Fundación Ambiente y Recursos Naturales (FARN) ${ }^{6}$, que elaboró mientras se desempeñaba como su director ejecutivo. NAPOLI, al mismo tiempo, remarca que, más allá del sostenimiento de la protesta socioambiental, "la temática ambiental no ha logrado ocupar en los últimos años un lugar destacado dentro de la agenda pública, y que fueron pocas las medidas, planes o iniciativas que lograron transformarse en políticas públicas destinadas a atender

\footnotetext{
${ }^{2}$ COBBETT, W., Advice to Young Men, 1829, citado por WALDROW, J., Derecho y desacuerdos, Marcial Pons, Madrid, 2003, p.324.

${ }^{3}$ GARGARELLA, R., El derecho a la protesta. El primer derecho, Ad-Hoc, Buenos Aires, 2005, p. 85.

${ }^{4}$ Ibidem, pp. 197 y 198.

${ }^{5}$ Ibidem, p.198.

${ }^{6}$ NAPOLI, A., "La participación ciudadana como motor de la agenda ambiental", FARN, Informe Ambiental Anual 2014, Buenos Aires, 2014, p. 34.
} 
a este tipo de situaciones"7.

En este marco, la hipótesis de investigación en este trabajo, en cuanto horizonte que orienta el camino de investigación, es la siguiente: la participación ciudadana en materia ambiental en la Argentina constituye el motor para el desarrollo normativo, la restitución de derechos a través del sistema judicial, el control social de las decisiones gubernamentales y la innovación jurídica para el goce efectivo del derecho al ambiente sano. En otras palabras, la participación social construye las causas ambientales al mismo tiempo que la legislación ambiental, si bien esta última adopta un criterio restrictivo respecto a la participación ciudadana. Por ello, existe una tensión entre la participación ciudadana- entendida como movimiento social o como derecho positivo $-\mathrm{y}$ las instituciones públicas, siendo esta tensión la que permite dinamizar y expandir el derecho al ambiente sano.

Para adentrarme en este tema, adopté una perspectiva metodológica interdisciplinaria y una estrategia de investigación orientada a la triangulación metodológica, con el propósito de contrastar la teoría y la práctica en materia de participación ciudadana. La estrategia de relevamiento de datos consistió en desarrollar los puntos que se mencionan a continuación:

a) La revisión de la legislación para conocer los mecanismos formales previstos para la participación ciudadana en materia ambiental: Constitución Nacional de la República Argentina/1994 (reformada), de 15 de diciembre (arts. 41 y 43); Ley 25.675/2002, de 6 de noviembre, General del Ambiente; Ley 25.831/2003, de 26 de noviembre, de Libre Acceso a la Información Ambiental; y Ley 26.618/2006, de 15 de noviembre, de la creación de la Autoridad de Cuenca Matanza-Riachuelo (ACUMAR) como ente de derecho público interjurisdiccional en el ámbito de la Secretaría de Ambiente y Desarrollo Sustentable de la Jefatura de Gabinete de Ministros ${ }^{8}$.

b) El estudio de casos emblemáticos en materia de derecho al ambiente sano teniendo en cuenta tanto el movimiento socioambiental como las repercusiones judiciales en diferentes conflictos localizados en: Esquel, "No a la mina" (2002-2003); Gualeguaychú, "No a las papeleras. Sí a la vida" (2005-2010); y cuenca Matanza-Riachuelo, saneamiento

\footnotetext{
${ }^{7}$ Ibidem.

${ }^{8}$ Los artículos de la legislación referidos a la temática que trata este artículo se encuentran trascriptos en el anexo.
} 
ambiental (2004-2008) .

c) La realización de entrevistas con informantes clave, doctores y doctorandos en derecho e investigadores en materia de derecho ambiental del Instituto de Investigaciones Ambrosio Gioja de la Facultad de Derecho de la Universidad de Buenos Aires (UBA) ${ }^{10}$.

d) El análisis de información institucional de organizaciones no gubernamentales (ONG) ambientales: Greenpeace y FARN.

Como reflexiones preliminares en materia de metodología, quiero mencionar, por una parte, que el trabajo con la legislación y los casos me orientó en la construcción de una tipología de formas de participación ciudadana en conflictos ambientales. Los casos territoriales facilitan la construcción de un catálogo de movilización del activismo verde. Y, por otra, las entrevistas con investigadores fueron relevantes para desnaturalizar la mirada en relación con cómo surgen las demandas y los intereses de los actores que se movilizan en torno a esta causa y con el impacto de las acciones promovidas desde las ONG, así como para contar con un panorama sobre la realidad social de los vecinos afectados por la contaminación de las aguas en la cuenca Matanza-Riachuelo.

\section{DESARROLLO: LA PARTICIPACIÓN CIUDADANA EN CONFLICTOS} AMBIENTALES

El abordaje de la participación ciudadana en conflictos ambientales en la Argentina requiere inicialmente contar con un marco teórico-conceptual que facilite la comprensión del sentido y del alcance de la acción colectiva. La legislación define un conjunto de mecanismos formales previstos para la promoción de la participación ciudadana en materia ambiental. En este camino también se presentan tres casos significativos de

\footnotetext{
9 Se aclara que la periodización de los conflictos ambientales corresponde al momento de mayor dinamismo; desde ya se contempla que la formación del movimiento en algún caso puede ser previa y/o contar con antecedentes, mientras que las repercusiones de la participación ciudadana incluso continuaron en el tiempo. Sobre metodología de casos en conflictos ambientales, véase MERLINSKY, M. G., "La espiral del conflicto. Una propuesta metodológica para realizar estudios de caso en el análisis de conflictos ambientales”, Merlinsky, María Gabriela, Cartografía del conflicto ambiental en Argentina, CLACSO CICCUS, Buenos Aires, 2013a.

${ }^{10}$ Agradezco su tiempo y generosidad a la Dra. Clara Minaverry, al Dr. Mariano Ferro y a la abogada Violeta Radovich (entrevistas realizadas en Buenos Aires en agosto y septiembre de 2016). En lo sucesivo, las entrevistas que se mencionen serán las aquí referidas.
} 
activismo verde que tuvieron lugar a inicios del siglo XXI en la Argentina, con el propósito de ilustrar y visualizar la dinámica de los conflictos socioambientales en la práctica. A partir de estas experiencias se confecciona una tipología de formas de participación ciudadana y se introducen estrategias de incidencia de la sociedad civil en materia ambiental. Cada uno de estos aspectos se despliega a continuación.

\section{Marco teórico-conceptual}

Dilucidar el significado de la expresión participación ciudadana resulta central para comprender el activismo verde. La Real Academia Española (RAE) define la voz participar como: "Tomar parte en algo" ${ }^{11}$. Desde una perspectiva sociológica, la participación ciudadana ambiental significa el poder expresar la propia voz en torno a una cuestión de interés o de afectación, en este caso colectiva, lo cual da lugar a acciones colectivas y sobre todo vinculadas a "tomar la calle", es decir, el espacio público. Este enfoque teórico también suele traducir esta forma de expresión colectiva "en las calles" como propias de la acción de los movimientos sociales y/o las protestas sociales, siendo estos otros conceptos aplicables desde las ciencias sociales en el análisis de este tipo de hechos socio-ambientales. Asimismo, se incluye a la participación ciudadana en temáticas del ambiente dentro del andamiaje conceptual de los nuevos movimientos sociales, que se encuentran integrados más específicamente en esta materia por el denominado movimiento verde.

La democracia participativa brinda un estimulante contexto para pensar el activismo verde. José Luis RAMÍREZ GONZÁLEZ, reflexionando sobre la participación en los países nórdicos, sostiene lo siguiente: "Participación es actuación participativa y participación cívica es la manera de obrar en que consiste la democracia, considerada como forma de actuar y no como estructura. [...] la democracia es un obrar que tiene su fin y su valor en sí misma"12. Esta concepción le permite demostrar el sentido procesual de la participación, que de este modo se posiciona como un indicador cuantitativo y cualitativo significativo de la "temperatura democrática" de una sociedad concreta, ya sea

\footnotetext{
${ }^{11}$ Consulta realizada en el sitio de internet de la RAE el 10 de agosto de 2016.

12 RAMÍREZ GONZÁLEZ, J., "La participación ciudadana en los países nórdicos”, Conferencia Europea sobre Participación Ciudadana en los Municipios, Córdoba, 1992, s/p.
} 
en el plano local, regional o nacional ${ }^{13}$. Lo mismo sucede con la participación en temáticas ambientales que logran dar cuenta de la democratización del ejercicio del derecho al ambiente sano. Esta manera de formar parte en lo social cristaliza en la apropiación social de una dimensión novedosa para la defensa y la conquista de derechos de incidencia colectiva, dada la indivisibilidad del ambiente y su trascendencia tanto para la sociedad en su conjunto como para las generaciones venideras.

La configuración que logre la expresión social del activismo verde (participación ciudadana, acción colectiva, movimiento social y/o protesta social) dependerá tanto del peso específico de la acción social que se promueva en el caso particular de cada conflicto ambiental como de la percepción de los actores involucrados, de la opinión pública y del propio Gobierno. Se trata de un complejo entramado sociopolítico que procesa el conflicto ambiental tornándolo una causa legítima y audible o un intento de reclamo fracasado.

Para comprender cómo se construye una causa ambiental, resulta necesario partir de la literatura que se ocupa de la construcción de causas humanitarias y de bien público. Desde la teoría de la acción colectiva se esgrime su centralidad para la transformación de los escenarios políticos. Como sostiene Sidney TARROW ${ }^{14}$, el poder de la acción colectiva resulta crucial para incidir en las decisiones gubernamentales, teniendo en cuenta que para la coordinación y el mantenimiento de las acciones colectivas los movimientos se ven influidos por su contexto y, en particular, por las oportunidades políticas. Por una parte, Oliver FILLIEULE ${ }^{15}$ entiende la acción colectiva como la persecución de la política por otros medios, y, por otra, se refiere a la disponibilidad de los repertorios de acción y a las estructuras de oportunidad que la tornan posible en la práctica social.

En este abordaje de la acción colectiva se advierten diferentes niveles de participación ciudadana, que Tomás ALBERICH NISTAL clasifica en grados sucesivos de complejidad e involucramiento social del siguiente modo: 1) información-formación; 2) consulta y

\footnotetext{
${ }^{13}$ Ibidem.

${ }^{14}$ TARROW, S., El poder en movimiento. Los movimientos sociales, la acción colectiva y la política, Alianza Editorial, Madrid, 1994.

${ }^{15}$ FILLIEULE, O., "Mobilisation des ressources”, Le Digol, C. (dir.), Dictionnaire de sociologie, ebook, Universalis, 2015.
} 
debate; y 3) cogestión ${ }^{16}$.El primer nivel señala que el acceso a la información es determinante para la participación de los vecinos y los afectados. Este punto es clave para distinguir la participación de la información, es decir, no resultan equivalentes, ya que la información constituye un requisito que abre el camino de la participación y, por este motivo, representa un elemento imprescindible para la acción, si bien no la constituye. Sin embargo, resulta preciso que la información sea comprendida, para lo cual se requiere un proceso de formación previa que incluya, por ejemplo, las normativas legales, las repercusiones de los procesos productivos en el ambiente, las alternativas existentes y los mecanismos de participación previstos en las leyes.

El segundo nivel de participación se orienta a que los afectados expresen su opinión y expongan propuestas, críticas, sugerencias y planes alternativos de acción frente al conflicto. En este nivel se constituye una fase de diálogo entre los representantes y los ciudadanos orientada a lograr acuerdos consensuados. Gracias a los dos primeros niveles se puede ejercer un control social sobre las acciones del Estado y/o del mercado. El tercer nivel en materia de gestión compartida genera un mecanismo de toma de decisiones en forma conjunta y de ejecución participativa por los miembros de una colectividad. Se trata de una participación directa en el gobierno.

Este abordaje en niveles remite a la metáfora de la escalera de la participación, que ha sido retomada por numerosos autores y resulta muy útil para visualizar las múltiples posibilidades de desarrollo del involucramiento ciudadano en el espacio público, desde formas de escasa participación hasta constituir un genuino poder ciudadano. En el marco de este esquema, la participación ciudadana puede concretarse en diversos espacios sociales, ya sea en la base a partir de los propios afectados o vecinos del territorio en conflicto ambiental (movimientos de base o grass roots), o bien en las estructuras de segundo orden como son las ONG ambientalistas. En ambos casos se visibiliza un activismo por el ambiente, aunque desde ya se generan expresiones particulares en cada caso. Las acciones de las ONG se orientan en general a un activismo experto que se vincula a un saber técnico, por ejemplo, el derecho y las políticas públicas específicos en

\footnotetext{
16 ALBERICH NISTAL, T., "Participación ciudadana”, Reyes, Román (dir.), Diccionario Crítico de Ciencias Sociales, Ed. Plaza y Valdés, Madrid y México, 2009, s/p. Recuperado el 10 de agosto de 2016, de: 〈http://pendientedemigracion.ucm.es/info/eurotheo/diccionario/P/participacion_ciudadana.htm>.
} 
la materia. En esta conjunción, de acuerdo con Johanna SIMÉNANT, se entrelazan saberes expertos y saberes militantes que impulsan la participación ciudadana ${ }^{17}$.

\section{Mecanismos formales en la legislación}

La Ley 25.675/2002, de 6 de noviembre, General del Ambiente, en cuanto ley de presupuestos mínimos ambientales, operacionaliza el mandato constitucional de la protección del ambiente y la promoción del desarrollo sostenible establecido en el artículo 41 de la Constitución Nacional. Esta ley incluye tres capítulos de relevancia trascendente para la definición de la participación ciudadana en el derecho positivo: educación ambiental (arts. 14 y 15), información ambiental (arts. 16, 17 y 18) y participación ciudadana propiamente dicha (arts. 19, 20 y 21).

La educación es definida como un "instrumento básico" y un "proceso continuo y permanente" para la educación formal y no formal (arts. 14 y 15). Sin duda, existe un enorme potencial de trabajo en esta materia y muchas deudas pendientes catorce años después de que se sancionara la Ley General del Ambiente en la Argentina. En materia de información ambiental, la Ley es amplia en la definición, aunque no tanto en la forma de implementación efectiva; así, establece que los habitantes obtienen el derecho a la información, mientras quelas personas físicas o jurídicas, públicas o privadas, la obligación de brindarla. Se designa al Consejo Federal del Medio Ambiente (COFEMA) como autoridad encargada de elaborar un "sistema nacional integrado de información". El punto central radica en que se establece que el Gobierno será responsable de informar tanto sobre "el estado del ambiente" como sobre "los posibles efectos que sobre él puedan provocar las actividades antrópicas actuales y proyectadas" (art. 18). También se impone al Poder Ejecutivo la carga de elaborar un informe anual sobre la situación ambiental de la Argentina, que deberá ser presentado en el Congreso de la Nación y que "contendrá un análisis y evaluación sobre el estado de la sustentabilidad ambiental en lo ecológico, económico, social y cultural de todo el territorio nacional" (art. 18). FARN ha alertado sobre la demora en la producción de estos informes, ya que el Informe Nacional sobre el Estado del Ambiente fue elaborado por la Secretaría de Ambiente y Desarrollo

\footnotetext{
${ }^{17}$ SIMÉANT, J., "Friches, hybrides et contrebandes: sur la circulation et a puissance militantes des discours savants", Hamman, Philippe; Méon, Jean-Matthieu y Verrier, Benoit (dirs.), Discours savants, discours militants: Mélange des genres,L`Harmattan,París, 2002, pp. 22-26.
} 
Sustentable de la Nación en el año 2012, lo cual equivale a un retraso de diez años desde la sanción de la Ley 25.675/2002, de 6 de noviembre, General del Ambiente ${ }^{18}$.

Como ya se ha adelantado, el último punto consiste en la participación ciudadana propiamente dicha. Aquí se instituye en forma positiva, por una parte, el derecho de toda persona "a ser consultada y a opinar en procedimientos administrativos que se relacionen con la preservación y protección del ambiente" (art. 19). Y, por otra, se establece el deber estatal a consultar a la población, ya que la Ley dispone lo siguiente: "Las autoridades deberán institucionalizar procedimientos de consultas o audiencias públicas como instancias obligatorias para la autorización de aquellas actividades que puedan generar efectos negativos y significativos sobre el ambiente" (art. 20). No obstante, se aclara que estos procedimientos de consulta no serán vinculantes para las autoridades. El último artículo de esta sección promueve la participación "en los procedimientos de evaluación de impacto ambiental y en los planes y programas de ordenamiento ambiental del territorio, en particular, en las etapas de planificación y evaluación de resultados" (art. 21).

Las falencias en la implementación de los mecanismos de consulta en la gestión ambiental constituyen una temática destacada y recurrente en la realidad argentina, siendo uno de los elementos que originan los conflictos socioambientales. Un análisis interesante de este articulado se puede realizar teniendo en cuenta los niveles de involucramiento social, presentados previamente, tal como se puede visualizar en el siguiente cuadro:

${ }^{18}$ NAPOLI, “La participación...," cit., p. 35. 
Cuadro 1: Tipología de participación ciudadana según la Ley 25.675/2002, de 6 de noviembre, General del Ambiente, clasificada por nivel de participación.

Sección Ley 25.675/2002

/ Nivel de participación ciudadana

Información ambiental

Educación ambiental

Participación ciudadana
Información - Consulta y debate Cogestión

Formación

$\mathrm{X}$

$\mathrm{X}$

Fuente: elaboración propia sobre la base de la Ley 25.675/2002, de 6 de noviembre, General del Ambiente, y teorías sobre la participación ciudadana.

Esta clasificación de los contenidos de la Ley por niveles de participación facilita graficar la concentración de formas de participación en los dos primeros niveles, mientras que el último de cogestión se encontraría más débilmente representado en la legislación. En términos cualitativos, el segundo nivel supone lograr acuerdos consensuados, lo cual no estaría clara ni definitivamente garantizado con mecanismos de participación no vinculantes. En vista de la magnitud de los conflictos ambientales en todo el país, sería poco prudente afirmar que gracias a los mecanismos de nivel de información y formación, por una parte, y de consulta y debate, por otra, se ha logrado efectivamente un control social sobre las acciones del Estado y/o del mercado. La realidad, lamentablemente, parecería demostrar lo contrario y señalaría que en la actualidad nos encontramos muy lejos de un modelo de cogestión en materia de política pública ambiental.

\section{Casos emblemáticos: Esquel, Gualeguaychú y cuenca Matanza-Riachuelo}

En el contexto histórico de la conflictividad ambiental en el país, la propuesta de este apartado consiste en mostrar puntualmente las acciones colectivas desplegadas y el resultado logrado en los casos escogidos, que fueron: la resistencia a la mina de oro y plata en Esquel; la oposición a la instalación de plantas de celulosa en la vera del río Uruguay en Gualeguaychú; y el reclamo por el saneamiento ambiental en la cuenca 
Matanza-Riachuelo. Con el propósito de comprender tanto los formatos como los efectos de la participación social, presento a continuación en forma sintética los casos emblemáticos de participación ciudadana mencionados en pos de garantizar el derecho constitucional al ambiente sano en la Argentina. Vale la pena aclarar que el análisis resulta más exhaustivo en el caso de la cuenca Matanza-Riachuelo, lo cual se debe a la propia naturaleza del conflicto, los actores intervinientes y el impacto del caso, que llegó a tratarse en el máximo tribunal del país, sin que esto desmerezca la relevancia de la movilización socioambiental gestada en los otros dos casos que se abordan en este artículo.

En primer lugar, el conflicto ambiental en la ciudad de Esquel (provincia de Chubut) ${ }^{19}$ situada en la cordillera de los Andes - por el proyecto de instalación de una mina de oro generó un movimiento ciudadano de altísima participación cuyo lema era "No a la mina". Esta participación ciudadana desplegó múltiples acciones: marchas, la conformación de la Asamblea de Vecinos Autoconvocados por el No a la Mina, charlas, muestras de cine, pintadas de murales, la judicialización del conflicto "causa Villivar" ${ }^{20} \mathrm{y}$, como hito fundamental, un plebiscito sobre la instalación de una mina de oro y plata ${ }^{21}$. El plebiscito, celebrado el 23 de marzo de 2003, fue convocado por parte de las autoridades locales a raíz de la movilización social, y “contó con la participación voluntaria del 75\% del padrón electoral, más de la media de las elecciones generales"22. En este se impuso con una abrumadora mayoría el "no" al proyecto de la multinacional Median Gold con el 81\% de los votos (11.046 votantes), mientras que a favor de la mina se pronunciaron el $17 \%$ de

\footnotetext{
${ }^{19}$ Para el censo correspondiente al año 2010 se conoció una población en Esquel de 32.758 personas, lo cual ubica a la localidad como la más poblada de la cordillera correspondiente a la provincia de Chubut y en cuarto lugar general en la provincia, superando incluso levemente a la población que habita en la capital provincial establecida en la ciudad de Rawson. Del mismo modo, constituye la localidad más poblada de la Patagonia andina, siguiendo a la ciudad de Bariloche, en la provincia de Río Negro. Recuperado el 10 de octubre de 2015, de: <http://www.estadistica.chubut.gov.ar/home/archivos/Censo2010/poblacion/datos_oficiales_2010.pdf>.

${ }^{20}$ Carátula completa: "Villivar, Silvana N. C/ Provincia del Chubut y otros s/amparo", 2007.

${ }^{21}$ El mecanismo de plebiscito, conocido también como consulta popular o referéndum, se engloba en los institutos de democracia semidirecta, fue previsto en la constitución provincial de Chubut y se encuentra reglamentado por ley desde el año 1999.

${ }^{22}$ URDINEZ, M., "Mecanismos de participación y control ciudadano: El plebiscito en Esquel”, IV Jornadas de Jóvenes Investigadores. Instituto de Investigaciones Gino Germani, Facultad de Ciencias Sociales, Universidad de Buenos Aires, Buenos Aires, 2007, p. 1. Recuperado el 10 de diciembre de 2012, de: $<$ http://webiigg.sociales.uba.ar/iigg/jovenes_investigadores/4jornadasjovenes/EJES/Eje\%2010\%20Derec ho\%20Ciudadania\%20Democracia/Ponencias/URDINEZ,\%20Mar\%EDa\%20Victoria.pdf>.
} 
los votantes ${ }^{23}$. Como contrapunto: "El gobierno provincial y el intendente trataron de desactivar cualquier posibilidad de cuestionamiento hacia el proyecto minero, instaló en los medios la idea de que la mina se hacía sí o sí”, según recordó Gustavo Macayo, uno de los abogados e integrante de la asamblea. Quien también remarcó y "pidió no olvidar” que hubo “muchos vecinos por el 'no' que fueron agredidos, perseguidos por patotas, víctimas de espionaje y amenazas"24.

El peso político del plebiscito fue tan contundente que implicó que el Gobierno no pudiera autorizar la mina. Como impacto de este activismo verde, se incrementaron los niveles de protección en materia ambiental para la explotación minera, de acuerdo con la Ley provincial 5001/2003, de 9 de abril, de prohibición de la actividad minera a cielo abierto y de la producción con cianuro en la provincia del Chubut. Este movimiento de protesta ambiental se convirtió en un hito por el éxito de su reclamo al haber logrado evitar la instalación de la mina en su territorio; su forma de expresión del descontento y de organización colectiva expandió sus efectos en la promoción de asambleas ambientales en todo el país y, a su vez, motorizó la conformación de la Unión de Asambleas Comunitarias (UAC). De todos modos, es interesante recordar que la forma de organización asamblearia emergió en el país con la crisis sociopolítica de diciembre de 2001, la cual constituye un antecedente de esta forma de acción colectiva alrededor de la temática ambiental.

\footnotetext{
${ }^{23}$ Ibidem.

${ }^{24}$ ARANDA, D., "Hace 10 años se hacía el primer plebiscito antiminero. Cuando Esquel dijo no", Página/12, Buenos Aires, 23 de marzo de 2013, s/p. Recuperado el 23 de marzo de 2013, de: $<$ http://www.pagina12.com.ar/diario/sociedad/3-216410-2013-03-23.html>.
} 
Imagen: Vecinos de Esquel marchando bajo la consigna "No a la mina".

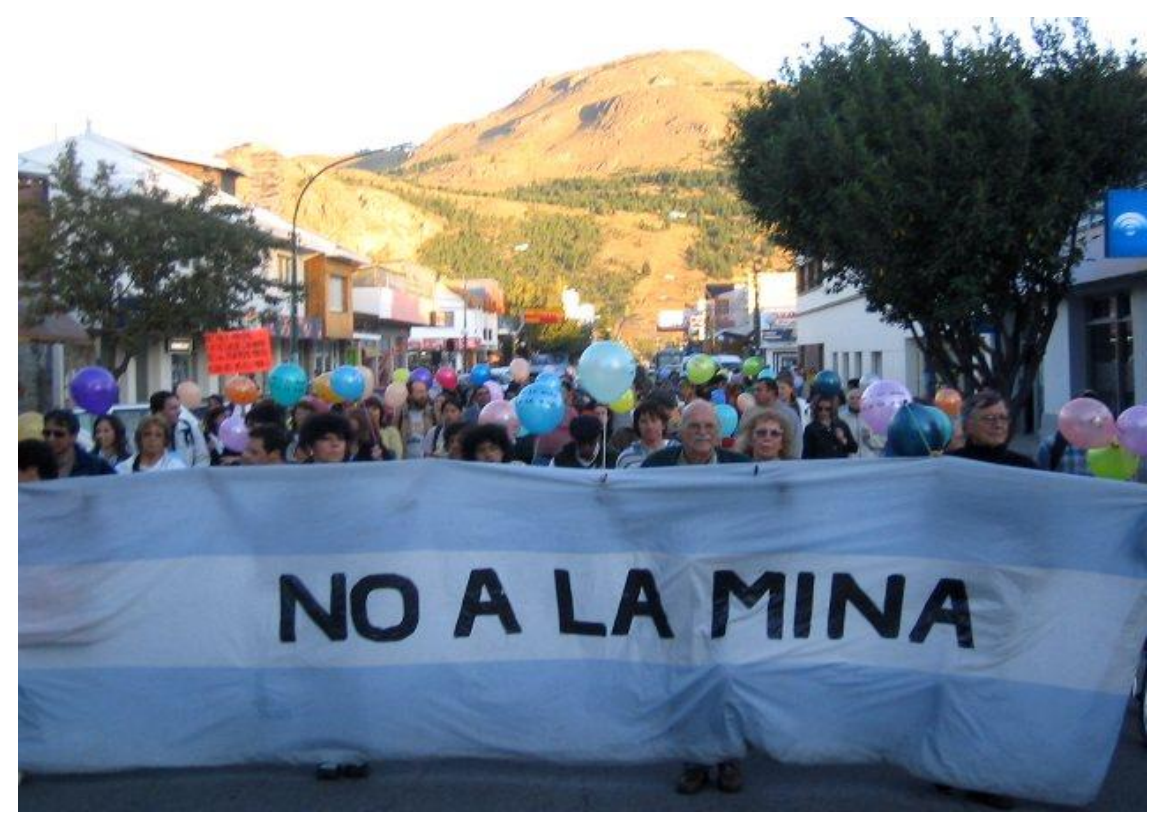

Fuente: Diario del Oeste.

En segundo lugar, en Gualeguaychú (provincia de Entre Ríos) se desató un conflicto ambiental por el proyecto de emplazamiento de dos plantas de celulosa, llamadas "papeleras" por los manifestantes, en las márgenes del río Uruguay-en territorio uruguayo-, lo que dio lugar al eslogan "No a las papeleras. Sí a la vida". Se trató de un conflicto transfronterizo de alta intensidad, gran movilización social y larga duración. Los vecinos se coordinaron con el movimiento ambientalista en el Uruguay; se organizaron con el formato de Asamblea Ciudadana Ambiental de Gualeguaychú y se dieron una forma de participación horizontal; generaron contenidos sobre el conflicto para los medios de comunicación y la comunidad; participaron difundiendo la problemática en establecimientos educativos y en otras ciudades del país; cortaron rutas y el Puente Internacional Libertador General San Martín; generaron sus propios informes técnicos tanto sobre aspectos legales, económicos y de salud pública como de impacto ambiental; y conminaron al Gobierno Nacional a tomar posición sobre el tema, quien demandó al Uruguay por la violación del "Estatuto del Río Uruguay" 25 ante la Corte Internacional de

\footnotetext{
${ }^{25}$ Se trata de un convenio internacional celebrado entre la República Oriental del Uruguay y la República Argentina en el año 1976, en el marco del Tratado del Río de La Plata y su Frente Marítimo del año 1973, su texto se encuentra disponible en: <http://servicios.infoleg.gob.ar/infolegInternet/anexos/3500039999/38458/norma.htm>.
} 
Justicia (CIJ), con sede en La Haya ${ }^{26}$. Greenpeace promovió acciones en torno al conflicto en forma tardía a su estallido. Entre sus intervenciones se destacó una protesta no tradicional, la cual tuvo lugar en el marco de la IV Cumbre Unión Europea-América Latina y el Caribe, realizada en Viena el 12 de mayo de 2006. En ese momento, la reina del carnaval de Gualeguaychú ingresó con su atuendo típico en la reunión con una pancarta donde se exponía el reclamo argentino por la instalación de las plantas de celulosa, con lo que se logró incidir en la agenda mundial en relación con esta cuestión.

Finalmente, la CIJ dictó el fallo definitivo el 20 de abril de 2010 en forma desfavorable para la Argentina, ya que, si bien se resolvió que el Uruguay había violado sus obligaciones emanadas del Estatuto del Río Uruguay - donde se establece el requisito de informar de buena fe-, también se dictaminó la desproporcionalidad del cierre de la planta de Botnia cuando la Argentina si bien se había demostrado que algunos parámetros de contaminación se habían elevado, falló a la hora de probar que la planta de celulosa era la causante de la contaminación de las aguas del río.. La Corte entendió que el Uruguay no había violado sus obligaciones para evitar la contaminación ambiental en el río Uruguay. Sin embargo, determinó que ambos países deberían realizar un monitoreo conjunto del río aplicando el Estatuto del Río Uruguay y a través de la Comisión Administradora del Río Uruguay.

\footnotetext{
${ }^{26}$ Información de este caso se encuentra disponible en los siguientes trabajos: MERLINSKY, M. G., "Nuevos repertorios de acción colectiva y conflicto ambiental: una cronología del conflicto por la instalación de las plantas de celulosa en el Río Uruguay”, Garavaglia, Juan Carlos y Merklen, Denis (coords.): El conflicto de las papeleras entre Uruguay y Argentina-Dossier Revista Nuevos Mundos, Questions du temps présent, 2008.Recuperado el 10 de agosto de 2016, de: https://nuevomundo.revues.org/16412;SANNAZZARO, J., “Controversias científico-públicas. El caso del conflicto por las 'papeleras' entre Argentina y Uruguay y la participación ciudadana”, Revista CTS, núm. 17, vol. 6, abril de 2011, pp. 213-239; y SANNAZZARO, J., "Participación ciudadana en conflictos ambientales en Latinoamérica: el caso 'Papeleras' y la asamblea ciudadana ambiental”, XV Encuentro de Latinoamericanistas Españoles, 2012, Trama editorial, Madrid, pp. 1474-1487.
} 
Imagen 2: Protesta en el Puente Internacional Libertador General San Martín en Gualeguaychú.

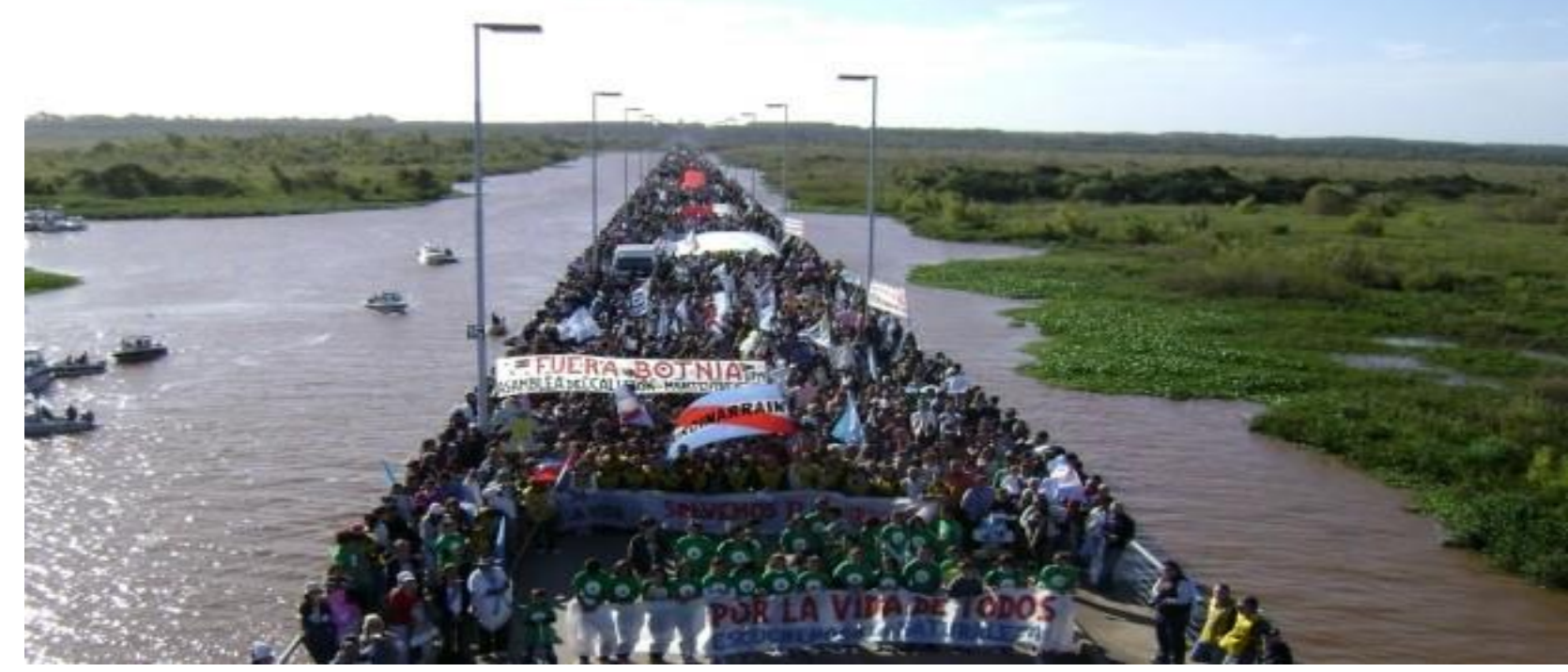

Fuente: BigBangNews.

En tercer lugar está el caso de la cuenca Matanza-Riachuelo, administrada actualmente por la ACUMAR, creada por la Ley 26.168/2006, de15 de noviembre, bajo jurisdicción del Gobierno Nacional, la provincia de Buenos Aires y la Ciudad Autónoma de Buenos Aires. La cuenca Matanza-Riachuelo tiene aproximadamente un curso de agua de $60 \mathrm{~km}$, con una anchura media de $35 \mathrm{~m}$ y una superficie de $2.200 \mathrm{~km}^{2}$, y comprende parte de la ciudad de Buenos Aires y de los municipios Almirante Brown, Avellaneda, Cañuelas, Esteban Echeverría, General Las Heras, La Matanza, Lanús, Lomas de Zamora, Marcos Paz, Merlo y San Vicente. El Riachuelo surca el Área Metropolitana de Buenos Aires (AMBA), y genera una frontera en un territorio que se encuentra vinculado social, política y ambientalmente. Se trata de un conflicto histórico por grave contaminación ambiental de larga duración donde se encuentran involucrados una multiplicidad de actores en un territorio extenso y heterogéneo. Se estima que en la influencia territorial de la cuenca habitan cinco millones de personas, aunque es relevante destacar que la cuenca en sí misma resulta poco visibilizada como espacio socioambiental, de ahí la escasa identidad que se genera entre las personas como habitantes de la cuenca. Este aspecto incide en la conformación sociocultural del conflicto ambiental y en la movilización posible entre los habitantes de la zona. 
El impulso determinante por el saneamiento de la cuenca y la reparación de los daños a la población se logró judicialmente con el caso conocido como "causa Mendoza"27, que fue promovido a partir del año 2004 por diecisiete vecinos de la zona y por un conjunto de ONG como terceras partes, y en el que también participó el Defensor del Pueblo de la Nación. Este caso se transformó en un hito por el activismo de la propia Corte Suprema de Justicia de la Nación (CSJN), que tomaba en sus manos un caso de contaminación con más de dos siglos de historia. El 8 de julio de 2008, la CSJN, a través de su fallo en esta causa, determinó tanto las responsabilidades institucionales para implementar las obras y las acciones de saneamiento ambiental como los plazos de estas y las multas pasibles de ser aplicadas ante eventuales incumplimientos. En el fallo se obliga a ACUMAR a llevar a cabo un programa cuyos objetivos son: 1) la mejora de la calidad de vida de los habitantes de la cuenca; 2) la recomposición del ambiente en todos sus componentes (agua, aire y suelo); y 3) la prevención de daños con suficiente y razonable grado de predicción.

Asimismo, un aspecto clave de la decisión de la CSJN consistió en "habilitar la participación ciudadana en el control del cumplimiento del Plan de Saneamiento y del programa fijado en el presente", y en "encomendar al Defensor del Pueblo de la Nación la coordinación de dicha participación, mediante la conformación de un cuerpo colegiado en el que participarán los representantes de las organizaciones no gubernamentales que intervienen en esta causa en condición de terceros interesados" ${ }^{28}$. En consecuencia, a través de la resolución, la CSJN conformó un cuerpo colegiado para el control del Plan Integral de Saneamiento Ambiental de la Cuenca Matanza-Riachuelo, que quedó integrado por el Defensor del Pueblo de la Nación y un conjunto de ONG. Para conformar

\footnotetext{
${ }^{27}$ La carátula completa es la siguiente: "Mendoza, Beatriz Silvia y otros c/ Estado Nacional y otros s/daños y perjuicios (daños derivados de la contaminación ambiental del Río Matanza - Riachuelo)”. En esta causa se responsabilizaba por daños y perjuicios al Estado Nacional, la provincia de Buenos Aires, la Ciudad Autónoma de Buenos Aires y 44 empresas. La demanda posteriormente se amplió hacia los catorce municipios de la provincia de Buenos Aires por los que se extiende la cuenca Matanza-Riachuelo. Un análisis exhaustivo se encuentra en MERLINSKY, M. G., Política, derechos y justicia ambiental. El conflicto del Riachuelo, Fondo de Cultura Económica, Buenos Aires, 2013b.

${ }^{28}$ Corte Suprema de Justicia de la Nación, "Mendoza, Beatriz Silvia y otros c/ Estado Nacional y otros s/daños y perjuicios (daños derivados de la contaminación ambiental del Río Matanza - Riachuelo)”, 2008, M. 1569. XL, p. 28 (considerandos $5 .^{\circ}$ y $\left.6 .^{\circ}\right)$.
} 
este cuerpo, se presentaron once $\mathrm{ONG}$, de las cuales fueron seleccionadas las ocho siguientes: Fundación Metropolitana, FARN, Greenpeace, Centro de Estudios Legales y Sociales (CELS), Asociación de Vecinos de La Boca, Asociación Ciudadana por los Derechos Humanos (ACDH), Poder Ciudadano y Fundación Ciudad. En otras palabras, el fallo genera formas de participación institucionalizadas: audiencias públicas, Plan de Saneamiento y mecanismos de control social a través de un cuerpo colegiado. Es decir, nos encontramos frente a la creación pretoriana por parte de la Corte de mecanismos para que la población pueda formar parte de la gestión ambiental.

Un punto relevante a considerar es el rol de las ONG ambientales como promotoras de la participación ciudadana. Como un caso testigo, es interesante tener en cuenta que FARN elaboró un diagnóstico donde esbozó las dos problemáticas centrales que afectan al ejercicio de la participación social para el monitoreo del saneamiento de la cuenca Matanza-Riachuelo, para lo que tuvo en consideración la capacidad de los actores locales y la construcción de la problemática del saneamiento a nivel local:

Por un lado, los actores locales tienen capacidad limitada de acceder a la información pública necesaria para monitorear el saneamiento de la cuenca. Es así que en muchos casos el Estado cuenta con esta información pero no es fácilmente accesible para los vecinos. Asimismo, la información puede estar disponible, pero en forma fragmentada, dispersa en diversos organismos y reparticiones, lo cual hace difícil y costoso su acceso. Finalmente, la falta de integración de la información limita su efectividad como insumo para las acciones de monitoreo.

Por otra parte, la segunda problemática se relaciona con que la demanda local por el saneamiento del Riachuelo está desarticulada. Los reclamos y las protestas vecinales por hechos de contaminación se focalizan territorial y temporalmente en casos puntuales (un derrame determinado; un basural específico, etc.), y en muchos casos no trascienden ni son suficientemente conocidos en el resto de la Cuenca. Esto limita sustancialmente el impacto que podrían tener estas acciones locales con respecto a las políticas generales de saneamiento y control de la contaminación en la cuenca ${ }^{29}$.

A partir de este diagnóstico, FARN, junto con la Fundación Ciudad y el Foro de Periodismo Argentino (FOPEA), impulsó el Programa Monitoreo Social del Saneamiento de la Cuenca Matanza-Riachuelo - Fortaleciendo la voz y la acción local. Se trata de un programa de control social del saneamiento que logró implementarse gracias al

\footnotetext{
${ }^{29}$ Consultado en el sitio web de Fundación Metropolitana, comunicado del año 2012, recuperado el 10 de agosto de 2015. Información disponible en: http://metropolitana.org.ar/idm/una-iniciativa-para-fortalecerla-capacidad-de-monitoreo-social-de-los-residentes-y-grupos-vecinales-de-la-cuenca-matanza-riachuelo/.
} 
financiamiento de la Unión Europa a través de la convocatoria para actores no estatales y autoridades locales en el desarrollo, por un monto de $206.638 \operatorname{euros}^{30}$. El programa estuvo vigente entre los años 2012 y 2014 y su objetivo consistió en "fortalecer la capacidad de monitoreo social de los residentes y grupos vecinales de la Cuenca y potenciar la incidencia ciudadana en las políticas públicas que se implementan en el territorio".

Este proyecto contemplaba diversas estrategias para promover la participación de los habitantes de la cuenca. En primer lugar, "generar y fortalecer una red de actores locales para monitorear el saneamiento y el control de la contaminación en la cuenca a partir de reportes en el terreno". En segundo lugar, "desarrollar herramientas y espacios comunicacionales que den voz y visibilidad a los reclamos locales en relación a la problemática socio-ambiental de la cuenca". En tercer lugar, "realizar ante las autoridades de control ambiental el seguimiento de las principales categorías de denuncias y reportes realizados por los actores locales para dar escala a los reclamos individuales y potenciar su impacto en las políticas públicas” (web Fundación Metropolitana, 2012).

El programa buscaba concretar las estrategias mencionadas a través de acciones tendientes a la visibilización del conflicto y a la socialización de la información relativa a la problemática ambiental, para lo cual se recurrió a las nuevas tecnologías de la comunicación y la información ${ }^{31}$. Las acciones del programa se mencionan a continuación $^{32}$ :

a) "[...] una red de actores locales que monitoreen los avances del plan de saneamiento y reporten hechos de contaminación que detecten", para lo cual se creó el Fondo de Respuesta, que financiaba propuestas de monitoreo locales ${ }^{33}$;

b) “[...] talleres para capacitar a los vecinos y ciudadanos comprometidos con el

\footnotetext{
$30 \quad$ Fuente: Unión Europea. Disponible en: $<$ http://eeas.europa.eu/delegations/argentina/press_corner/all_news/news/2012/20120928_riachuelo_es.ht $\mathrm{m}>$.

${ }^{31}$ RAMÍREZ CUESTA, A., "Programa de Participación Ciudadana en el Saneamiento del Riachuelo", FARN, Informe Ambiental Anual 2015, Buenos Aires, 2015.
}

32 Información difundida por FARN, FOPEA y Unión Europea. Disponible en: $<$ http://farn.org.ar/archives/Campa\%C3\%B1as/monitoreo-social-del-saneamiento-de-la-cuenca-matanzariachuelo; http://www.fopea.org/monitoreo-social-del-saneamiento-de-la-cuenca-matanza-riachuelo/> y $<$ http://eeas.europa.eu/delegations/argentina/press_corner/all_news/news/2012/20120928_riachuelo_es.ht m>. Un análisis detallado se encuentra en RAMÍREZ CUESTA, "Programa...”, cit., 2015.

33 La nómina de proyectos financiados se encuentra disponible en: <http://farn.org.ar/riachuelocmr/monitoreoriachuelo/fondosrespuestariachuelo >. 
monitoreo y control social" 34;

c) '[...] un sistema informático que permita recibir y 'cruzar' los reportes de los actores locales con la información pública";

a) "[...] una plataforma de información geo-referenciada, de acceso libre y gratuito" llamada ¿Qué pasa Riachuelo? ${ }^{35}$; y

e) un documental titulado La vuelta al Río ${ }^{36}$.

Más allá del enorme impacto en torno al "caso Mendoza", que inaugura una nueva etapa en el involucramiento de la CSJN en materia de derechos de incidencia colectiva, existen críticas de algunos sectores al formato de la participación ciudadana en este caso. Esta crítica plantea que la participación se concentra en los denunciantes en la causa judicial y en las ONG vinculadas al caso. En otras palabras, señalan como déficit que no se ha logrado integrar a gran parte de los damnificados por la contaminación ambiental y el daño a la salud. Incluso se ha llegado a poner en tela de juicio el impacto real y la utilización de las herramientas tecnológicas aportadas por el proyecto de FARN y la Unión Europea porque, más allá de lo interesantes y novedosas que sean, el acento negativo recae en la cuantificación de la apropiación y la utilización efectiva de la herramienta por las comunidades y los interesados en el conflicto.

Otra cuestión sumamente relevante, que surge del trabajo de campo realizado en la cuenca por investigadores del Instituto de Investigaciones Ambrosio Gioja de la UBA, consiste en que se advierte una superposición de conflictos sociales que logran su expresión a través de la demanda ambiental como punta de lanza. Es decir, la demanda ambiental equivale a la demanda con legitimidad para expresarse y al mismo tiempo se transforma en soporte o conducto de otras necesidades de las poblaciones que no logran otro canal para vehiculizarse. En concreto, se presenta el caso de "Villa Inflamable", donde los pobladores de la zona, sumidos en condiciones de vida de extrema pobreza, graves enfermedades e inseguridad personal, encontraron la forma de esbozar reclamos sociales para el acceso a la vivienda digna por medio de las demandas ambientales.

\footnotetext{
${ }^{34}$ Detalle de los talleres disponible en: <http://farn.org.ar/riachuelocmr/monitoreoriachuelo/agenda-detalleres>.

${ }^{35}$ Sitio disponible en el siguiente enlace: http://quepasariachuelo.org.ar/.

36 El documental se encuentra disponible en el siguiente enlace: <http://farn.org.ar/archives/Campa\%C3\%B1as/documental-la-vuelta-al-rio. Información oficial del documental en: http://www.lavueltaalrio.org/documental>.
} 
Imagen 3: Asentamiento precario en la orilla del Riachuelo.

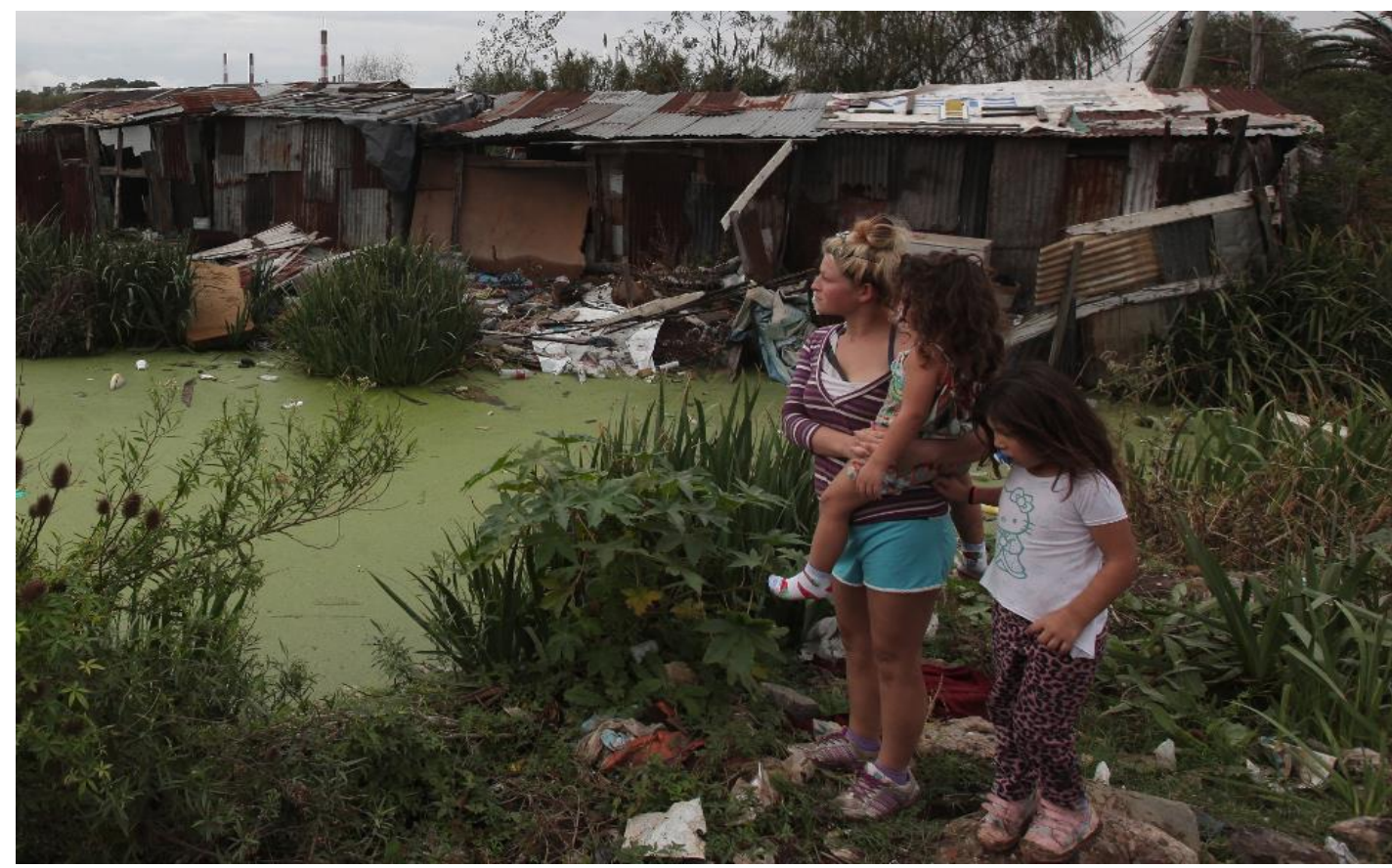

Fuente: Diario La Nación, 2014.

\section{Tipología de las acciones colectivas y estrategias de incidencia}

La construcción de una tipología de las acciones de participación ciudadana resulta un aporte para reflexionar sobre su origen, sus formas de expresión, su reconocimiento legal y su impacto en relación con el objetivo de preservar el ambiente. A primera vista es factible contrastar la multiplicidad de formas posibles de participación ciudadana en el marco de la inventiva social con los mecanismos enunciados en forma positiva por la legislación, entre los que se encuentran: la educación formal y no formal, la solicitud de información, las audiencias públicas, los procedimientos de consulta, los procedimientos de evaluación de impacto ambiental, la creación de comisiones de participación social y otras formas de control social (véanse cuadros 2, 3 y 5). Las grandes estrategias de la participación ciudadana, desde la perspectiva de la protesta social, consisten centralmente, por su impacto social y político, en "tomar la calle" por medio de diversas formas de ocupar el espacio público y en la estrategia de intervención jurídica en pos de la defensa del interés público. No obstante, el repertorio de participación ciudadana ofrece un conjunto amplio de opciones, desde las acciones directas en el espacio público hasta la organización interna de los ciudadanos, la movilización de la opinión pública, la promoción de la educación, la generación de un saber experto sobre el conflicto ambiental 
o las protestas no tradicionales (véase cuadro 2).

Para profundizar en este análisis, se vuelve imprescindible distinguirlas acciones colectivas desarrolladas por los movimientos sociales y las organizaciones de la sociedad civil (véanse cuadros 2 y 3 ) de las formas de participación ciudadana previstas por la legislación o bien creadas en forma pretoriana por la CSJN (véanse cuadros 4 y 5). Entre los mecanismos de participación ciudadana conceptualizados por las organizaciones de la sociedad civil involucradas en el activismo verde se destacan los siguientes: la participación en la formulación de las políticas públicas ambientales, el acceso a la información pública ambiental, el acceso a la justicia y al litigio ambiental, los mecanismos de monitoreo ciudadano y las campañas (véase cuadro 3). La participación ciudadana, de acuerdo con la legislación ambiental, se focaliza en las siguientes tres dimensiones: la información ambiental, la educación ambiental y la participación ciudadana desde un enfoque limitativo (véase cuadro 4). El derecho positivo prevé los siguientes mecanismos de participación ciudadana: educación formal y no formal, la solicitud de información, las audiencias públicas, los procedimientos de consulta, el reconocimiento de personerías especiales a las ONG para promover amparos y participar en consejos de control de los servicios públicos, los procedimientos de evaluación del impacto ambiental, los programas de ordenamiento ambiental, el reconocimiento de accesos procesales de protección de los derechos difusos (amparo ambiental),los programas de ordenamiento ambiental, la comisión de participación social y el control social (véase cuadro 5).

Las acciones colectivas emanadas desde la base y la propia sociedad civil despliegan un abanico más amplio y creativo de opciones $y$, al mismo tiempo, disputan fuertemente la cogestión de los bienes ambientales. En particular, las ONG plantean la participación ciudadana en el momento de la formulación de las políticas públicas ambientales, lo cual requiere del fortalecimiento de las herramientas de intervención en la gestión de lo público por la ciudadanía. Por lo contrario, las formas previstas por la legislación resultan restrictivas y se concentran en los niveles de información y consulta, aunque la dificultad mayor consiste en el grado de implementación de los mecanismos formales establecidos por las leyes. La creación pretoriana de mecanismos de participación ciudadana a través de las sentencias de la CSJN podría llegar a abonar en el terreno de la cogestión si la implementación de sus decisiones por los poderes ejecutivos llegara a ser exitosa (en este punto se fortalece un espacio para investigaciones empíricas en el largo plazo que vayan 
analizando el devenir de estos mecanismos).

También resulta productivo adoptar una dimensión temporal para focalizar en los momentos en que surgen las acciones colectivas en el movimiento verde $y$, en contraste, cuando se encuentran previstos por el ordenamiento positivo (véase cuadros 5 y 6 ). En el primer caso, se observa que la participación en las acciones colectivas se verifica en momentos en que un emprendimiento de explotación de recursos naturales es autorizado a funcionar y se temen efectos nocivos sobre el ambiente, o bien cuando esta explotación ha repercutido a lo largo del tiempo en forma negativa en el ambiente y/o la salud de la población. En el segundo caso, se evidencian ofertas de participación ciudadana en el ordenamiento positivo en materia de acceso a la información, a nivel consultivo y, en forma muy incipiente, lo que podría considerarse una participación en un nivel considerado de cogestión como lo sería la efectiva participación ciudadana en los estudios de impacto ambiental.

Las buenas prácticas de la participación ciudadana en materia ambiental remiten al interés por la preservación del ambiente sano. Desde la sociedad civil estas prácticas suponen expresar la propia voz sobre el cuidado de los bienes ambientales y promover estrategias para "tomar parte" que contribuyan aponer en cuestión las formas de explotación de los recursos naturales impulsadas por el Estado y/o el mercado. Se destacan las siguientes: la conformación de asambleas ambientales de ciudadanos con formas de funcionamiento propias de la democracia directa y horizontales (vale aclarar, sin liderazgos formales); los pedidos de información al Estado como mecanismo que permite conocer el estado del ambiente y los planes de gestión; la promoción de litigios ambientales por el cese del daño ambiental y la recomposición del ambiente (en general, impulsados bajo la forma de amparos ambientales); la apropiación social del conocimiento experto para generar sus propios estudios técnicos; y la gesta de mecanismos de control ciudadano. 
Cuadro 2: Participación ciudadana de acuerdo con experiencias de conflictos ambientales en Esquel, Gualeguaychú y la cuenca Matanza-Riachuelo en la Argentina.

\begin{tabular}{|c|c|c|c|}
\hline Denominación & $\begin{array}{l}\text { Especificidades de las } \\
\text { acciones }\end{array}$ & Tipo de acción & Objetivos \\
\hline Tomar la calle & $\begin{array}{l}\text { Corte de ruta, puente, } \\
\text { manifestaciones, } \\
\text { marchas }\end{array}$ & $\begin{array}{l}\text { Acción directa } \\
\text { colectiva en el } \\
\text { espacio público }\end{array}$ & $\begin{array}{l}\text { Dar visibilidad al reclamo, situar el } \\
\text { tema en la agenda política, lograr } \\
\text { apoyo popular, incidir en la política } \\
\text { pública de gobierno. }\end{array}$ \\
\hline $\begin{array}{l}\text { Asamblea de } \\
\text { vecinos/ } \\
\text { ambiental/ } \\
\text { juvenil }\end{array}$ & $\begin{array}{l}\text { Reuniones de vecinos } \\
\text { y/o afectados, plan de } \\
\text { trabajo, programación } \\
\text { de acciones }\end{array}$ & $\begin{array}{l}\text { Acción de } \\
\text { organización interna } \\
\text { y de coordinación } \\
\text { con otros grupos }\end{array}$ & $\begin{array}{l}\text { Nucleamiento de interesados en } \\
\text { torno al tema en común, definición } \\
\text { de mecanismos de difusión de } \\
\text { información y de toma de decisiones } \\
\text { para el plan de acción, coordinación } \\
\text { del activismo. }\end{array}$ \\
\hline $\begin{array}{l}\text { Difusión, } \\
\text { promoción y } \\
\text { sensibilización }\end{array}$ & $\begin{array}{l}\text { Performances, } \\
\text { murales, cine, } \\
\text { presencia en medios } \\
\text { de comunicación }\end{array}$ & $\begin{array}{l}\text { Acciones colectivas } \\
\text { de comunicación y } \\
\text { difusión }\end{array}$ & $\begin{array}{l}\text { Difundir el mensaje, lograr apoyo a } \\
\text { la causa, movilizar a la opinión } \\
\text { pública, hacer llegar el mensaje al } \\
\text { poder político. }\end{array}$ \\
\hline Petitorios & $\begin{array}{l}\text { Relevamiento de } \\
\text { firmas de apoyo }\end{array}$ & $\begin{array}{l}\text { Acción colectiva de } \\
\text { movilización pública }\end{array}$ & $\begin{array}{l}\text { Visibilizar el apoyo a la causa, } \\
\text { generar un aminoramiento del } \\
\text { rechazo al conflicto ambiental. }\end{array}$ \\
\hline $\begin{array}{l}\text { Judicialización } \\
\text { del conflicto }\end{array}$ & $\begin{array}{l}\text { Amparo ambiental, } \\
\text { acciones por cese y } \\
\text { reparación del daño }\end{array}$ & $\begin{array}{l}\text { Acción judicial } \\
\text { individual y/o } \\
\text { colectiva }\end{array}$ & $\begin{array}{l}\text { Cese de la acción que genera el daño } \\
\text { ambiental, restitución de derechos. }\end{array}$ \\
\hline $\begin{array}{l}\text { Educación y } \\
\text { sensibilización }\end{array}$ & $\begin{array}{l}\text { Charlas en } \\
\text { establecimientos } \\
\text { educativos de } \\
\text { diferentes niveles }\end{array}$ & $\begin{array}{l}\text { Acción en } \\
\text { instituciones } \\
\text { educativas }\end{array}$ & $\begin{array}{l}\text { Socializar conocimiento sobre la } \\
\text { problemática ambiental, generar } \\
\text { toma de conciencia ambiental e } \\
\text { involucramiento de las nuevas } \\
\text { generaciones. }\end{array}$ \\
\hline
\end{tabular}




\begin{tabular}{|l|l|l|l|}
\hline Conocimiento & $\begin{array}{l}\text { Elaboración de } \\
\text { informes técnicos } \\
\text { sobre el impacto } \\
\text { ambiental }\end{array}$ & $\begin{array}{l}\text { Acción de } \\
\text { promoción de saber } \\
\text { experto entre los } \\
\text { asambleístas, } \\
\text { organización en } \\
\text { grupos técnicos } \\
\text { interdisciplinarios } \\
\text { por áreas }\end{array}$ & $\begin{array}{l}\text { Generar sus propios informes } \\
\text { décnicos sobre el impacto ambiental, } \\
\text { disputar el saber científico-experto, } \\
\text { reponer su dimensión política. }\end{array}$ \\
\hline Protestas no \\
tradicionales & $\begin{array}{l}\text { Reina del carnaval de } \\
\text { Gualeguaychú en la } \\
\text { Cumbre Europa- } \\
\text { América Latina }\end{array}$ & Acción directa & $\begin{array}{l}\text { Visibilización pública e incidencia } \\
\text { en la agenda política a nivel nacional } \\
\text { e internacional. }\end{array}$ \\
\hline
\end{tabular}

Fuente: elaboración propia sobre la base de la información sobre los conflictos ambientales. 
Cuadro 3: Participación ciudadana de acuerdo con la conceptualización de las organizaciones de la sociedad civil involucradas en los conflictos ambientales en Esquel, Gualeguaychú y la cuenca Matanza-Riachuelo y enfocadas en el activismo verde.

\begin{tabular}{|c|c|c|c|}
\hline Denominación & Especificaciones & Fuente & Objetivos \\
\hline $\begin{array}{l}\text { Participación en la } \\
\text { formulación de las } \\
\text { políticas públicas } \\
\text { ambientales }\end{array}$ & $\begin{array}{l}\text { Audiencia pública, } \\
\text { plebiscitos }\end{array}$ & $\begin{array}{l}\text { FARN, Curso } \\
\text { Participación } \\
\text { Ciudadana y } \\
\text { Políticas } \\
\text { Ambientales }^{37}\end{array}$ & $\begin{array}{l}\text { Fortalecer } \\
\text { herramientas de } \\
\text { participación en la } \\
\text { formulación de } \\
\text { políticas públicas } \\
\text { ambientales. }\end{array}$ \\
\hline $\begin{array}{l}\text { Acceso a la } \\
\text { información pública } \\
\text { ambiental }\end{array}$ & $\begin{array}{l}\text { Acceso de los ciudadanos a } \\
\text { la información pública y las } \\
\text { obligaciones del Estado con } \\
\text { respecto a la generación de } \\
\text { la información. Plataformas, } \\
\text { pedido de informes. }\end{array}$ & $\begin{array}{l}\text { FARN, Curso } \\
\text { Participación } \\
\text { Ciudadana y } \\
\text { Políticas } \\
\text { Ambientales } \\
\text { Programa de } \\
\text { Monitoreo Social } \\
\text { (FARN y Unión } \\
\text { Europea) }\end{array}$ & $\begin{array}{l}\text { Acceder a la } \\
\text { información pública } \\
\text { como herramienta que } \\
\text { posibilita la } \\
\text { participación. }\end{array}$ \\
\hline $\begin{array}{l}\text { Acceso a la justicia y } \\
\text { litigio ambiental }\end{array}$ & $\begin{array}{l}\text { Acceso a la justicia, } \\
\text { impacto de la } \\
\text { judicialización de la agenda } \\
\text { ambiental }\end{array}$ & $\begin{array}{l}\text { FARN, Curso } \\
\text { Participación } \\
\text { Ciudadana y } \\
\text { Políticas } \\
\text { Ambientales }\end{array}$ & $\begin{array}{l}\text { Derecho al acceso a la } \\
\text { justicia en materia } \\
\text { ambiental. }\end{array}$ \\
\hline
\end{tabular}

${ }^{37}$ Información disponible en: http://farn.org.ar/capacitaciones/cursosonline/participacion-ciudadana. 


\begin{tabular}{|c|c|c|c|}
\hline $\begin{array}{l}\text { Mecanismos de } \\
\text { monitoreo ciudadano }\end{array}$ & $\begin{array}{l}\text { Mecanismos de control } \\
\text { ciudadano en las políticas } \\
\text { ambientales (talleres, redes, } \\
\text { fondos para proyectos) }\end{array}$ & $\begin{array}{l}\text { FARN, Curso } \\
\text { Participación } \\
\text { Ciudadana y } \\
\text { Políticas } \\
\text { Ambientales } \\
\text { Programa de } \\
\text { Monitoreo Social } \\
\text { (FARN y Unión } \\
\text { Europea) }\end{array}$ & $\begin{array}{l}\text { Incrementar el control } \\
\text { social de la política } \\
\text { ambiental. }\end{array}$ \\
\hline Campañas & $\begin{array}{l}\text { Herramientas para generar } \\
\text { impacto comunicacional en } \\
\text { acciones generalmente } \\
\text { relámpago }\end{array}$ & Greenpeace & $\begin{array}{l}\text { Visibilidad pública y } \\
\text { presión política }\end{array}$ \\
\hline
\end{tabular}

Fuente: elaboración propia sobre la base de la información pública de las organizaciones ambientales. 
Cuadro 4: Participación ciudadana en los casos de conflictos ambientales en Esquel, Gualeguaychú y la cuenca Matanza-Riachuelo de acuerdo con las dimensiones previstas por el derecho positivo por niveles de participación.

\begin{tabular}{|c|c|c|c|}
\hline $\begin{array}{l}\text { Sección Ley } \\
25.675 / 2002 / \text { Nivel de } \\
\text { participación ciudadana }\end{array}$ & Información - Formación & Consulta y debate & Cogestión \\
\hline Información ambiental & $\begin{array}{c}\text { Cuenca Matanza- } \\
\text { Riachuelo: pedidos de } \\
\text { informes }\end{array}$ & --- & --- \\
\hline Educación ambiental & --- & --- & --- \\
\hline Participación ciudadana & --- & $\begin{array}{c}\text { Esquel: plebiscito } \\
\text { Cuenca Matanza- } \\
\text { Riachuelo: audiencias } \\
\text { públicas }\end{array}$ & $\begin{array}{l}\text { Cuenca Matanza- } \\
\text { Riachuelo: } \\
\text { cuerpo colegiado }\end{array}$ \\
\hline
\end{tabular}

Fuente: elaboración propia sobre la base de la Ley 25.675/2002, de 6 de noviembre, General del Ambiente, teorías sobre la participación ciudadana e información sobre los conflictos. 
Cuadro 5: Participación ciudadana de acuerdo con los mecanismos prescriptos por el derecho positivo o por la creación pretoriana de la CSJN a partir de los casos de los conflictos ambientales desarrollados en Esquel, Gualeguaychú y la cuenca MatanzaRiachuelo.

\begin{tabular}{|c|c|c|}
\hline Denominación & Legislación marco & Decisiones de la CSJN \\
\hline Educación formal y no formal & $\begin{array}{l}\text { Ley } 25.675 / 2002 \text {, de } 6 \\
\text { de noviembre, General } \\
\text { del Ambiente }\end{array}$ & --- \\
\hline Solicitud de información & $\begin{array}{l}\text { Ley } 25.831 / 2003, \text { de } \\
26 \text { de noviembre, de } \\
\text { Libre Acceso a la } \\
\text { Información } \\
\text { Ambiental }\end{array}$ & --- \\
\hline Audiencias públicas & $\begin{array}{l}\text { Ley } 25.675 / 2002 \text {, de } 6 \\
\text { de noviembre, General } \\
\text { del Ambiente }\end{array}$ & "causa Mendoza" \\
\hline Procedimientos de consulta & $\begin{array}{l}\text { Ley } 25.675 / 2002 \text {, de } 6 \\
\text { de noviembre, General } \\
\text { del Ambiente }\end{array}$ & --- \\
\hline $\begin{array}{l}\text { Reconocimiento de personerías } \\
\text { especiales a las ONG para promover } \\
\text { amparos y participar en consejos de } \\
\text { control de los servicios públicos }\end{array}$ & $\mathrm{CN}$ art. 43 & "causa Mendoza" \\
\hline $\begin{array}{l}\text { Procedimientos de evaluación de } \\
\text { impacto ambiental }\end{array}$ & $\begin{array}{l}\text { Ley } 25.675 / 2002 \text {, de } 6 \\
\text { de noviembre, General } \\
\text { del Ambiente }\end{array}$ & --- \\
\hline
\end{tabular}




\begin{tabular}{|l|l|c|}
\hline Programas de ordenamiento ambiental & $\begin{array}{l}\text { Ley 25.675/2002, de 6 } \\
\text { de noviembre, General } \\
\text { del Ambiente }\end{array}$ & --- \\
\hline $\begin{array}{l}\text { Reconocimiento de acciones procesales } \\
\text { de protección de los derechos difusos, } \\
\text { amparo ambiental }\end{array}$ & CN art. 43 & --- \\
\hline $\begin{array}{l}\text { Comisión de participación social (las } \\
\text { organizaciones y los grupos que } \\
\text { trabajan en la cuenca Matanza- } \\
\text { Riachuelo) }\end{array}$ & $\begin{array}{l}\text { Ley 26.618/2006, de } \\
15 \text { de noviembre, de la } \\
\text { Cuenca Matanza- } \\
\text { Riachuelo }\end{array}$ & --- \\
\hline Control social (el Cuerpo Colegiado) & $\begin{array}{l}\text { Ley 25.675/2002, de 6 } \\
\text { de noviembre, General } \\
\text { del Ambiente }\end{array}$ & "causa Mendoza" \\
\hline
\end{tabular}

Fuente: elaboración propia sobre la base de la Constitución Nacional de la Argentina $(\mathrm{CN})$, la Ley 25.675/2002, de 6 de noviembre, General del Ambiente; Ley 25.831/2003, de 26 de noviembre, de Libre Acceso a la Información Ambiental; Ley 26.618/2006, de 15 de noviembre, de la Cuenca Matanza-Riachuelo; y fallos de la CSJN. Se aclara que se toma la Ley como fuente de tipos ideales, ya que, debido a las características de este trabajo, no han sido especialmente relevadas. 
Cuadro 6: Participación ciudadana en los casos de los conflictos ambientales en Esquel, Gualeguaychú y la cuenca Matanza-Riachuelo de acuerdo con el momento temporal del impulso de las acciones colectivas por niveles de participación.

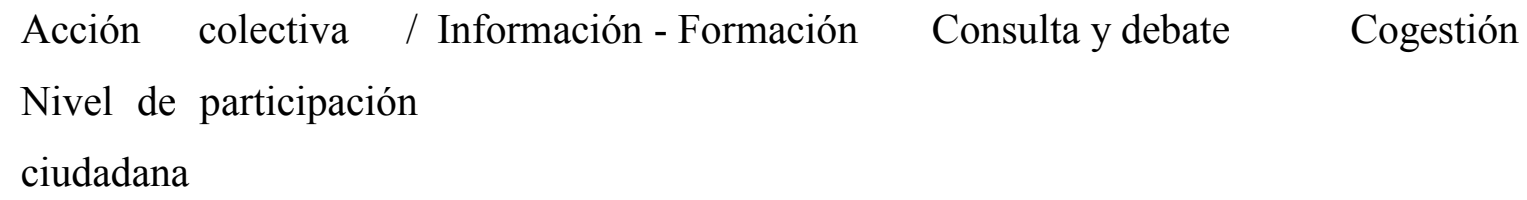

$\begin{array}{cccc}\text { Monitoreo del } & \text { bien Cuenca Matanza-Riachuelo: } & -- & \text { Cuenca Matanza- } \\ \text { jurídico } & \text { plataforma en línea para } & \text { Riachuelo: cuerpo } \\ & \text { difundir información de la } & \text { colegiado, control } \\ & \text { cuenca, pedidos de informes } & \text { social }\end{array}$

Fuente: elaboración propia sobre la base de la Ley 25.675/2002, de 6 de noviembre, General del Ambiente, teorías sobre la participación ciudadana e información sobre los conflictos. 


\section{CONCLUSIONES: LA FUERZA DEL ACTIVISMO VERDE}

Como ha pasado frecuentemente en la historia del derecho, la práctica social aventaja al derecho positivo al expresarse con mayor riqueza y legitimidad, y surge en forma previa en el tiempo y tensiona por el cambio en la política pública. Al igual que en el caso del derecho laboral, el derecho al ambiente sano emergió primero de las luchas de los movimientos sociales y luego se plasmó en la legislación, aunque es posible afirmar que en términos restrictivos. En otras palabras, la participación ciudadana se conforma necesariamente por las prácticas sociales, y no resulta posible su configuración por la determinación de artículos de una ley aunque lleve por título esa denominación. Las prácticas sociales vivas son las que pueden dinamizar y expandir el derecho al ambiente sano y expresar en forma más acabada el interés público. Muestra de ello se encuentra en los objetivos buscados por las acciones colectivas desplegadas por las poblaciones que protagonizaron los conflictos ambientales aquí presentados, entre los que se pueden resaltar: la visibilización de los reclamos en la población en general y ante el Gobierno; el fortalecimiento de los lazos sociales en torno a la problemática común que potencie el nucleamiento de activistas; la búsqueda del cese de la acción que genera el daño ambiental y la restitución de los derechos afectados; la socialización del conocimiento ambiental y la disputa del saber experto; y la incidencia en la política pública.

En contrapunto, estas páginas asimismo permiten sostener que la participación ciudadana más allá de figurar en la letra de una ley requiere de condiciones de posibilidad para llegar a concretarse en forma satisfactoria, tanto en términos cualitativos como cuantitativos. Esto quiere decir que poblaciones en estado de vulnerabilidad social difícilmente pueden participar y comprometerse, ya que, como planteaba GARGARELLA, la participación no se puede escindir de la organización socioeconómica ni de las condiciones materiales en un lugar y tiempo determinados ${ }^{38}$. Este es un punto clave a tener presente, ya que se requieren acciones positivas para mitigar la desventaja social en pos de favorecer la participación ciudadana; en esta línea puede encontrarse, en el caso de la cuenca MatanzaRiachuelo, el programa desarrollado por FARN con fondos de la Unión Europea.

La participación ciudadana podría idealmente instituirse en instancias previas a la irrupción de un conflicto ambiental a fin de tender justamente a prevenirlo o mitigarlo.

${ }^{38}$ GARGARELLA,El derecho...,cit., pp. 198-202. 
En este punto se requeriría la efectiva participación ciudadana en el momento del diseño de la política pública, lo que equivale a dar lugar a la toma de decisión en forma participativa, así como también a la hora de su evaluación. La actividad minera a cielo abierto constituye un buen ejemplo de decisiones de explotación del ambiente sin consulta previa a las poblaciones. La movilización social en Esquel sella con el plebiscito el derecho ciudadano a ser consultado ante proyectos que afecten al ambiente y su calidad de vida. A diferencia del marco de la consulta establecido por la Ley 25.675/2002, de 6 de noviembre, General del Ambiente, sería auspicioso que la opinión ciudadana fuera vinculante a fin de robustecer los mecanismos de democracia participativa en materia ambiental. El caso del reclamo del saneamiento de la cuenca Matanza-Riachuelo es un ejemplo diferente donde se verifican tanto el desarrollo normativo como sentencias judiciales favorables a la recomposición del ambiente y el control social en la gestión del Plan Integral de Saneamiento Ambiental de la Cuenca Matanza-Riachuelo. Es también en este conflicto donde el activismo de la CSJN, que equivale a un activismo desde arriba, introduce novedades trascendentes para la participación ciudadana como la fijación de los contenidos del Plan Integral de Saneamiento Ambiental de la Cuenca MatanzaRiachuelo y la creación de un cuerpo colegiado para su control social.

Con vistas a generar transformaciones reales orientadas a establecer las bases de una democracia participativa, resulta fundamental mejorar los indicadores de participación ciudadana en el nivel con menor incidencia, que actualmente, según se observa en los casos presentados, se corresponde con el de cogestión. Como así también es prioritario promover mecanismos de involucramiento social desde la propia planificación de la política pública ambiental, de forma que se genere un origen participativo en las decisiones sobre la vida en común. Es en estos puntos donde resulta crucial la concentración de fuertes esfuerzos para vehiculizar formas de participación ciudadana desde abajo que sean institucionalizadas o bien logren institucionalizarse y se mantengan en el tiempo, lo cual a su vez promueva la retroalimentación y el fortalecimiento de las prácticas de "tomar parte" de la población sin la imperiosa necesidad de recurrir como única opción a la protesta socioambiental para ser escuchados. Otro aspecto con enorme potencial es el relativo a la educación ambiental, donde los ciudadanos cuentan con el derecho a recibir información y herramientas para luchar por su derecho al ambiente sano, siendo hora que este derecho pueda ser efectivamente ejercido en la Argentina. 
El conflicto ambiental pone en evidencia la ausencia de mecanismos estatales consolidados y extendidos para la escucha de la demanda social y del interés público en torno al ambiente. Por esta causa, el activismo verde emerge como forma de poner en tensión la debilidad o incluso la inexistencia de canales de participación y gestión participativa del ambiente, disputando tener voz y voto en este terreno fundamental de la vida pública.

\section{ANEXOS}

\section{Constitución de la República Argentina}

Artículo 41. Todos los habitantes gozan del derecho a un ambiente sano, equilibrado, apto para el desarrollo humano y para que las actividades productivas satisfagan las necesidades presentes sin comprometer las de las generaciones futuras; y tienen el deber de preservarlo. El daño ambiental generará prioritariamente la obligación de recomponer, según lo establezca la ley. Las autoridades proveerán a la protección de este derecho, a la utilización racional de los recursos naturales, a la preservación del patrimonio natural y cultural y de la diversidad biológica, y a la información y educación ambientales. Corresponde a la Nación dictar las normas que contengan los presupuestos mínimos de protección, y a las provincias, las necesarias para complementarlas, sin que aquellas alteren las jurisdicciones locales. Se prohíbe el ingreso al territorio nacional de residuos actual o potencialmente peligrosos, y de los radiactivos.

Artículo 43. Toda persona puede interponer acción expedita y rápida de amparo, siempre que no exista otro medio judicial más idóneo, contra todo acto u omisión de autoridades públicas o de particulares, que en forma actual o inminente lesione, restrinja, altere o amenace, con arbitrariedad o ilegalidad manifiesta, derechos y garantías reconocidos por esta Constitución, un tratado o una ley. En el caso, el juez podrá declarar la inconstitucionalidad de la norma en que se funde el acto u omisión lesiva.

Podrán interponer esta acción contra cualquier forma de discriminación y en lo relativo a los derechos que protegen al ambiente, a la competencia, al usuario y al consumidor, así como a los derechos de incidencia colectiva en general, el afectado, el defensor del pueblo 
y las asociaciones que propendan a esos fines, registradas conforme a la ley, la que determinará los requisitos y formas de su organización.

Toda persona podrá interponer esta acción para tomar conocimiento de los datos a ella referidos y de su finalidad, que consten en registros o bancos de datos públicos, o los privados destinados a proveer informes, y en caso de falsedad o discriminación, para exigir la supresión, rectificación, confidencialidad o actualización de aquéllos. No podrá afectarse el secreto de las fuentes de información periodística.

Cuando el derecho lesionado, restringido, alterado o amenazado fuera la libertad física, o en caso de agravamiento ilegítimo en la forma o condiciones de detención, o en el de desaparición forzada de personas, la acción de hábeas corpus podrá ser interpuesta por el afectado o por cualquiera en su favor y el juez resolverá de inmediato, aun durante la vigencia del estado de sitio.

Fuente: InfoLEG.

$<\underline{\text { http://servicios.infoleg.gob.ar/infolegInternet/anexos/0-4999/804/norma.htm> }}$

\section{Ley General del Ambiente}

\section{Educación ambiental}

ARTÍCULO 14. La educación ambiental constituye el instrumento básico para generar en los ciudadanos, valores, comportamientos y actitudes que sean acordes con un ambiente equilibrado, propendan a la preservación de los recursos naturales y su utilización sostenible, y mejoren la calidad de vida de la población.

ARTÍCULO 15. La educación ambiental constituirá un proceso continuo y permanente, sometido a constante actualización que, como resultado de la orientación y articulación de las diversas disciplinas y experiencias educativas, deberá facilitar la percepción integral del ambiente y el desarrollo de una conciencia ambiental.

Las autoridades competentes deberán coordinar con los consejos federales de Medio Ambiente (COFEMA) y de Cultura y Educación, la implementación de planes y programas en los sistemas de educación, formal y no formal.

Las jurisdicciones, en función de los contenidos básicos determinados, instrumentarán los respectivos programas o currículos a través de las normas pertinentes. 
Información ambiental

ARTÍCULO 16. Las personas físicas y jurídicas, públicas o privadas, deberán proporcionar la información que esté relacionada con la calidad ambiental y referida a las actividades que desarrollan.

Todo habitante podrá obtener de las autoridades la información ambiental que administren y que no se encuentre contemplada legalmente como reservada.

ARTÍCULO 17. La autoridad de aplicación deberá desarrollar un sistema nacional integrado de información que administre los datos significativos y relevantes del ambiente, y evalúe la información ambiental disponible; asimismo, deberá proyectar y mantener un sistema de toma de datos sobre los parámetros ambientales básicos, estableciendo los mecanismos necesarios para la instrumentación efectiva a través del Consejo Federal de Medio Ambiente (COFEMA).

ARTÍCULO 18. Las autoridades serán responsables de informar sobre el estado del ambiente y los posibles efectos que sobre él puedan provocar las actividades antrópicas actuales y proyectadas.

El Poder Ejecutivo, a través de los organismos competentes, elaborará un informe anual sobre la situación ambiental del país que presentará al Congreso de la Nación. El referido informe contendrá un análisis y evaluación sobre el estado de la sustentabilidad ambiental en lo ecológico, económico, social y cultural de todo el territorio nacional.

\section{Participación ciudadana}

ARTÍCULO 19. Toda persona tiene derecho a ser consultada y a opinar en procedimientos administrativos que se relacionen con la preservación y protección del ambiente, que sean de incidencia general o particular, y de alcance general.

ARTÍCULO 20. Las autoridades deberán institucionalizar procedimientos de consultas o audiencias públicas como instancias obligatorias para la autorización de aquellas actividades que puedan generar efectos negativos y significativos sobre el ambiente.

La opinión u objeción de los participantes no será vinculante para las autoridades convocantes; pero en caso de que éstas presenten opinión contraria a los resultados alcanzados en la audiencia o consulta pública deberán fundamentarla y hacerla pública.

ARTÍCULO 21.La participación ciudadana deberá asegurarse, principalmente, en los procedimientos de evaluación de impacto ambiental y en los planes y programas de 
ordenamiento ambiental del territorio, en particular, en las etapas de planificación y evaluación de resultados.

Fuente: InfoLEG.

<http://servicios.infoleg.gob.ar/infolegInternet/anexos/75000-79999/79980/norma.htm>

\section{Ley de la Cuenca Matanza-Riachuelo}

Comisión de Participación Social.

ARTÍCULO $4^{\circ}$. Créase en el ámbito de la autoridad de Cuenca Matanza Riachuelo, una Comisión de Participación Social, con funciones consultivas. Esta Comisión estará integrada por representantes de las organizaciones con intereses en el área.

Fuente: ACUMAR.

$<$ http://www.acumar.gov.ar/normativa/1/resolucion-26168>

\section{Ley de Libre Acceso a la Información Ambiental}

ARTÍCULO $2^{\circ}$. Definición de información ambiental. Se entiende por información ambiental toda aquella información en cualquier forma de expresión o soporte relacionada con el ambiente, los recursos naturales o culturales y el desarrollo sustentable. En particular:

a) El estado del ambiente o alguno de sus componentes naturales o culturales, incluidas sus interacciones recíprocas, así como las actividades y obras que los afecten o puedan afectarlos significativamente;

b) Las políticas, planes, programas y acciones referidas a la gestión del ambiente.

ARTÍCULO $3^{\circ}$. Acceso a la información. El acceso a la información ambiental será libre y gratuito para toda persona física o jurídica, a excepción de aquellos gastos vinculados con los recursos utilizados para la entrega de la información solicitada. Para acceder a la información ambiental no será necesario acreditar razones ni interés determinado. Se deberá presentar formal solicitud ante quien corresponda, debiendo constar en la misma la información requerida y la identificación del o los solicitantes residentes en el país, salvo acuerdos con países u organismos internacionales sobre la base de la reciprocidad. 
En ningún caso el monto que se establezca para solventar los gastos vinculados con los recursos utilizados para la entrega de la información solicitada podrá implicar menoscabo alguno al ejercicio del derecho conferido por esta ley.

ARTÍCULO $4^{\circ}$. Sujetos obligados. Las autoridades competentes de los organismos públicos, y los titulares de las empresas prestadoras de servicios públicos, sean públicas, privadas o mixtas, están obligados a facilitar la información ambiental requerida en las condiciones establecidas por la presente ley y su reglamentación.

ARTÍCULO $5^{\circ}$. Procedimiento. Las autoridades competentes nacionales, provinciales y de la Ciudad de Buenos Aires, concertarán en el ámbito del Consejo Federal de Medio Ambiente (COFEMA) los criterios para establecer los procedimientos de acceso a la información ambiental en cada jurisdicción.

ARTÍCULO $6^{\circ}$. Centralización y difusión. La autoridad ambiental nacional, a través del área competente, cooperará para facilitar el acceso a la información ambiental, promoviendo la difusión del material informativo que se genere en las distintas jurisdicciones.

Fuente: InfoLEG.

http://servicios.infoleg.gob.ar/infolegInternet/anexos/90000-94999/91548/norma.htm

\section{BIBLIOGRAFÍA}

\section{Bibliografía citada y consultada}

ALBERICH NISTAL, T., "Participación ciudadana”, Reyes, Román (dir.), Diccionario Crítico de Ciencias Sociales, Ed. Plaza y Valdés, Madrid y México, 2009. Recuperado el 10 de agosto de 2016, de:

http://pendientedemigracion.ucm.es/info/eurotheo/diccionario/P/participacion_ciudadan a.htm

ANDRÉS, G. y WURSTEN, A., "El 'conflicto de las papeleras' como controversia tecnocientífica: un caso de empoderamiento social y participación ciudadana", Fundamentos en Humanidades, Universidad Nacional de San Luis, año XXII, número II, 2012, pp. 185-199. 
ARANDA, D., "Hace 10 años se hacía el primer plebiscito antiminero. Cuando Esquel dijo no", Página/12, Buenos Aires, 23 de marzo de 2013. Recuperado el 23 de marzo de 2013, de: <http://www.pagina12.com.ar/diario/sociedad/3-216410-2013-03-23.html>

FILlIEULE, O., "Mobilisation des ressources", Le Digol, C. (dir.), Dictionnaire de sociologie, ebook, Universalis, 2015.

GARGARELLA, R., El derecho a la protesta. El primer derecho, Ad-Hoc, Buenos Aires, 2005 .

MERLINSKY, M. G., "Nuevos repertorios de acción colectiva y conflicto ambiental: una cronología del conflicto por la instalación de las plantas de celulosa en el Río Uruguay", Garavaglia, Juan Carlos y Merklen, Denis (coords.): El conflicto de las papeleras entre Uruguay y Argentina - Dossier Revista Nuevos Mundos, Questions du temps présent, 2008. Recuperado el 10 de agosto de 2015, de: <https://nuevomundo.revues.org/16412>. MERLINSKY, M. G., “La espiral del conflicto. Una propuesta metodológica para realizar estudios de caso en el análisis de conflictos ambientales”, Merlinsky, María Gabriela, Cartografía del conflicto Ambiental en Argentina, CLACSO - CICCUS, Buenos Aires, 2013a.

MERLINSKY, M. G., Política, derechos y justicia ambiental. El conflicto del Riachuelo, Fondo de Cultura Económica, Buenos Aires, 2013b.

NAPOLI, A., "La Participación ciudadana como motor de la agenda ambiental”, FARN, Informe Ambiental Anual 2014, Buenos Aires, 2014, pp. 33-40.

RAMÍREZ CUESTA, A., "Programa de Participación Ciudadana en el Saneamiento del Riachuelo", FARN, Informe Ambiental Anual 2015, Buenos Aires, 2015, pp. 359-372.

RAMÍREZ GONZÁLEZ, J., "La participación ciudadana en los países nórdicos", Conferencia Europea sobre Participación Ciudadana en los Municipios, Córdoba, 1992.Recuperado el 10 de octubre de 2015, de: http://www.ub.edu/geocrit/sv-61.htm.

SANNAZZARO, J., "Controversias científico-públicas. El caso del conflicto por las 'papeleras' entre Argentina y Uruguay y la participación ciudadana”, Revista CTS, núm.17, vol. 6, abril de 2011, pp. 213-239.

SANNAZZARO, J., "Participación ciudadana en conflictos ambientales en Latinoamérica: el caso 'Papeleras' y la asamblea ciudadana ambiental”, XV Encuentro de Latinoamericanistas Españoles, 2012, Trama editorial, Madrid, pp. 1474-1487. 
SIMÉANT, J., "Friches, hybrides et contrebandes: sur la circulation et a puissance militantes des discours savants", Hamman, Philippe; Méon, Jean-Matthieu y Verrier, Benoit (dirs.), Discours savants, discours militants: Mélange des genres, L'Harmattan, París, 2002, pp. 17-53.

TARROW, S., El poder en movimiento. Los movimientos sociales, la acción colectiva y la política, Alianza Editorial, Madrid, 1994.

URDINEZ, M., "Mecanismos de participación y control ciudadano: El plebiscito en Esquel", IV Jornadas de Jóvenes Investigadores. Instituto de Investigaciones Gino Germani, Facultad de Ciencias Sociales, Universidad de Buenos Aires, Buenos Aires, 2007, 1. Recuperado el 10 de diciembre de 2012, de: $<$ http://webiigg.sociales.uba.ar/iigg/jovenes_investigadores/4jornadasjovenes/EJES/Eje \%2010\%20Derecho\%20Ciudadania\%20Democracia/Ponencias/URDINEZ,\%20Mar\%E Da\%20Victoria.pdf $>$.

WALDROW, J., Derecho y desacuerdos, Marcial Pons, Madrid, 2003.

\section{Jurisprudencia}

Corte Suprema de Justicia de la Nación, "Mendoza, Beatriz Silvia y otros c/ Estado Nacional y otros s/daños y perjuicios (daños derivados de la contaminación ambiental del Río Matanza - Riachuelo)”, 2008, M. 1569. XL.

Corte Suprema de Justicia de la Nación, "Villivar, Silvana N. C/ Provincia del Chubut y otros s/amparo", 2007.

\section{Sitios en internet}

ACUMAR: <http://www.acumar.gov.ar/>

Dirección General de Estadística y Censos, Provincia de Chubut, República Argentina: $<$ http://www.estadistica.chubut.gov.ar/>

FARN: <http://farn.org.ar/>

FOPEA: <http://www.fopea.org/>

Fundación Metropolitana: <http://metropolitana.org.ar/> 
Greenpeace: http://www.greenpeace.org/argentina/es/

InfoLEG, Información legislativa y documental, Ministerio de Justicia y Derechos Humanos, Presidencia de la Nación, República Argentina: $<$ http://servicios.infoleg.gob.ar/>

No a la mina: $<$ http://www.noalamina.org/>

No a las papeleras: <http://noalaspapeleras.com.ar/web/>

Proyecto Riachuelo: <http://proyectoriachuelo.blogspot.com.ar/2012/08/proyectovivo.html>

Real Academia Española: <http://www.rae.es/>

Unión Europea, delegación Argentina: <http://eeas.europa.eu/delegations/argentina/> 